\title{
Type II Acrocephalopolysyndactyly
}

National Cancer Institute

\section{Source}

National Cancer Institute. Type II Acrocephalopolysyndactyly. NCI Thesaurus. Code C98873.

An extremely rare autosomal recessive syndrome characterized by premature closure of cranial sutures leading to cone-shaped head, fusion of the digits, and the presence of more digits than normal. It may be associated with heart defects, single horseshoeshaped kidney, short stature, undescended testes, and mild mental retardation. 